Franz Pöchhacker*

\title{
Simultaneous Interpreting: A Functionalist Perspective
}

\begin{abstract}
The paper discusses a number of theoretical and methodological issues which arise when professional simultaneous conference interpreting (SI) is studied in light of the basic tenets of the functionalist theory of translation and interpreting (T\&I) proposed by Hans J. Vermeer (skopos theory). Based on a multi-level model of SI as a professional course of action the paper applies such functionalist notions as skopos, target culture, target-textual autonomy, and "coherence" to a case study of a three-day technical conference with professional SI between English and German.

In essence, it is argued that, on a general conceptual level, modelling SI in the framework of the general functionalist theory of Vermeer serves to bring into focus the crucial translational issues of situation, text, and culture. On the other hand, applying skopos-theoretical concepts to the study of a corpus of authentic professional SI reveals some limitations of the extent to which the general functionalist notions fit the specific practice of SI.
\end{abstract}

\section{Introduction}

\section{T and/or I}

The professional activities of translation and interpreting can, in many respects, be regarded as fraternal twins. Conceptually, they can even be considered as two sides of the same coin $(T+I=T \& I)$. As early as the 1960s translation scholars at Leipzig like Otto Kade and Albrecht Neubert tried to get a theoretical grip on the generic concept of translational activity as such, be it oral or in writing. Their choice of linguistics as the guiding discipline for research in T\&I, however plausible at the time, tended to favor translation research over the study of interpreting. After all, the paradigms of modern linguistics beyond the phonological level (structural semantics, transformational grammar,

* Franz Pöchhacker

Department of Translation and Interpreting,

University of Vienna

Gymnasiumstrasse 50

1190 Vienna $(A)$ 
contrastive linguistics, etc.) were largely geared to the analysis of written words and sentences rather than oral performance, the study of oral communication being rather messy with regard to research methodology. Thus, with few exceptions, the theory of (written) translation and the theory of (conference) interpreting parted company.

The "linguistic theory of translation" had little, if any, counterpart in the field of interpreting, where psychologists/psycholinguists and practitioners themselves took an approach of their own. Most notably among the latter, Danica Seleskovitch proposed her théorie du sens in explicit contradistinction to theories of linguistic meaning, which then tended to show little concern for the actual use of language in communication. Seleskovitch's theory, elaborated on for simultaneous interpreting by Lederer (1981), was easily and successfully applied to the teaching of interpreting and gained predominance as the largely undisputed school of thought in (conference) interpreting theory. With hindsight, Seleskovitch ushered in what Gile (1988:369) perceives as both "a promising initial phase" in interpreting research and theory and, due to a lack of systematic analysis of empirical data, "a subsequent period of stagnation". The latter prompted a new wave of interpreting research, which largely stresses the role of cognitive psychology as a guiding discipline for empirical ("scientific") research.

Obviously, the development of translation theory and interpreting theory over the past decades is much too complex to be summarized in a couple of introductory paragraphs. Translation research and theory has undergone tremendous diversification by drawing on a wide range of methods and models such as think-aloud protocols and text and discourse analysis. While, in principle, the same diversity could be attested to recent work in interpreting research, interpreting studies on the whole seems to be a somewhat narrower field: The choice of a more rigorously scientific approach relegates "personal theories" like the théorie du sens (Gile 1990) to the status of mere hypotheses and untested assumptions, prompting scientist-observers to label interpreting studies as a field "with little theoretical development" (Dillinger 1990:43). Within interpreting studies as well there is considerable agreement that after decades of investigation interpreting theory and research is still "under-developed" (Gile 1990:38 and this volume). More specifically on the relation of translation studies to interpreting studies, Matthews (1984:85) states that "if interpreting studies is 
considered as a separate discipline from translation studies, then it is lagging behind."

\section{Process vs. product}

Apart from the fact that, with few exceptions such as Stenzl (1983) and Shlesinger (1989a, b), interpreting research rarely draws on theoretical concepts developed for the study of texts and (written) translation, interpreting studies also tends to focus more narrowly on the cognitive "mechanics" of second-by-second processing rather than on holistic conceptions of text, situation, culture, and the entire course of action in a professional interpreting assignment. One might construe an unbroken tradition from Lederer's (1978:333) concern with "the connection between thinking and speaking (...) as it materializes with each segment of speech" to Gile's (1991:15) overall impression that "the most fundamental and frequently discussed issues in interpretation theory (...) revolve around the question: 'How does interpretation work?" Clearly, the focus of conference interpreting research is on elucidating the micro-level processes involved in this complex cognitive task, hence the affinity for the research paradigms of cognitive psychology.

T\&I theory for product-oriented interpreting research

Against the background crudely sketched above, the purpose of this paper is four-fold:

(1) to demonstrate the rationale for broadening the theoretical base of interpreting studies by drawing on concepts from translation theory;

(2) to create a theoretical if not methodological interface between research on translation and interpreting by building on comprehensive theoretical conceptions of translational activity (T\&I);

(3) to discuss the potential as well as the limitations of the functionalist theory of T\&I as developed by Vermeer (1983) and Holz-Mänttäri (1984) for the analysis of simultaneous conference interpreting (SI), and

(4) to show that interpreting researchers can find many exciting new challenges by taking a product-oriented approach to an interpreter's output as text-in-situation- $\&$-culture. 


\section{"The end justifies the translation"}

Theoretical accounts of translation in the 1960s and 1970s were largely inspired by the linguistic theories of the day and were primarily concerned with the relation between lingustic units, specifically in terms of the equivalence between source- and target-language texts. The 1970s then saw a reorientation in the study of language, away from abstract rules and systems toward the concrete use of language for a particular purpose, i.e. communication (cf. Snell-Hornby 1988). Into focus came the text and its function in a given communicative situation. Applying this functionalist view also to texts in translation, German translation scholars like Reiss (1971) and, more radically, Vermeer (1978) elevated the purpose (Greek: skopos) or intended function of the target text to the top-ranking principle governing the process of translation. More pointedly, Vermeer argues that the end justifies the means and thus the translation. The skopos theory, as a general theory of T\&I laid down in Reiss \& Vermeer (1984), defines T\&I as a process of cultural transfer according to a set of hierarchical principles. The purpose to be fulfilled by translation and interpreting is largely constrained by the target-culture recipients. In essence, the theory holds that the target text must first and foremost conform to the standard of intratextual coherence, i.e. it must "make sense" within its communicative situation and culture. Only in the second place must there be intertextual coherence, i.e. some relation of fidelity or loyalty (Nord 1991a) to the source text. In this functionalist conception the standard by which professional T\&I is to be judged is not the degree of equivalence with the original but the extent to which the target text functions as intended within its socio-cultural context.

If the skopos is the all-important variable, with everything else following from or depending on it, who determines it, and how? - The answer is readily apparent if T\&I is placed in its actual social context, as in Holz-Mänttäri's (1984) comprehensive theory of T\&I as a professional course of action (translatorisches Handeln). Professional T\&I is normally done "on assignment". Some individual or institution needs a text in order to establish communication across barriers of language and culture and commissions an expert to do the job. The skopos arises from the assignment, from the circumstances, requirements and ulterior motives, as it were, of the client. The particulars of the case must be made explicit, either by the client him/herself or, more 
typically, by the T\&I expert negotiating for specific information about the target text (audience, medium, time, place, occasion, etc.; cf. Nord 1991b).

In the case of (written) translation, the assignment, apart from the specifications mentioned above, is essentially the text to be translated. It is at this point, therefore, that one may begin to wonder whether and how this general theoretical conception of T\&I equally applies to oral translational activity as manifested, in particular, in simultaneous conference interpreting (SI). This question will be discussed below with particular reference to the notions of skopos, intratextual coherence, and (target) culture.

\section{SI in a functionalist framework}

Skopos in SI

Departing from Holz-Mänttäri's (1984) comprehensive theoretical conception of T\&I as a course of translatorial action within a complex network of social interaction, it is easy to show that in conference interpreting the relationship between the client and the interpreter (and between the conference assignment and the source text) is not as straightforward, at least in analytical terms, as in the case of (written) translation. The conference interpreter's client does not want $a$ text to be translated but needs a much more complex communicative event. Using Beaugrande \& Dressler's (1981) definition of "text" in its broadest sense, the conference can be viewed as an overarching sort of text comprised of a number of individual texts. This hypertext, as I would like to call it, is a holistic unit, i.e. it has properties amounting to more than the sum of its parts. Accepting, then, that the conference or hypertext is the "basic-level category" (Lakoff 1987) in the analysis of SI, it follows that the skopos in SI is situated at the level of the conference assignment as specified, for instance, in the standardized contract form adopted by AIIC, the International Association of Conference Interpreters. Unlike Vermeer (1989), who uses the notion of skopos also to refer to the function of the target text, I would suggest that it is not some particular target-text skopos but the hypertext skopos that governs the production of functional texts in SI. By way of example, one might think of the varying informational and commu- 
nicative needs at a specialized training seminar vs. a press conference or a round of political negotiations.

The point that there are indeed different types of meetings which require a different interpreting approach was made early on by such pioneers as Herbert (1952:81f) and is borne out by more recent attempts at establishing conference typologies (cf. Namy 1978, Gile 1989, Snelling 1989) as well as by empirical research on the varying needs and expectations of different user groups (Kurz 1993, Kopczyński 1994). In a questionnaire-based pilot survey among experienced conference interpreters (Pöchhacker 1994, chapter 4) seven hypertext (proto)types based on the conference typology proposed by Gile (1989) were differentiated by ratings on a continuous scale for five features: degree of structural complexity, cultural homogeneity of group, informational intensity, visual support material and information flow. An example of such a "hypertext profile" (Type 2: "Technical Conference") is provided in Fig. 1:

Fig. 1: Hypertext profile type 2 ("technical conference") 
Much more so than in written translation, the function of the individual text in SI can be perceived as a systemic variable in the communicative interplay of speaker(s) and listener(s) physically co-present at a given place and time. The situation, analyzed in terms of the individual interactants' roles, perceptions, dispositions, and intentions, as rooted in and reflecting general, specialized, individual, and contextual knowledge and competence (cf. the schematic model in Pöchhacker 1992), is the communicative "context" which determines the functional characteristics of the text. Ascertaining the function of an original speech or its interpretation is therefore not limited to the analysis of the text but can - and must - rely on the socio-psychological data and dynamics of the situation of interaction. This multi-level analytical framework can be graphically represented as in Fig. 2:

Fig. 2: Multi-level analytical framework for SI 
The above attempt at clarifying or, rather, specifying the general theoretical notion of skopos with a view to SI may have seemed like a mere exercise in terminology and definition. Indeed, hardly anything of what has been said so far poses any serious analytical challenge.

In the following, though, two issues will be raised which may bring out some potential limitations of the skopos-theoretical approach. The notions of intratextual coherence of a simultaneous interpretation, and of the (target) culture in SI will be discussed, first in conceptual terms and then by drawing on examples from a conference case study, so as to show to what extent the general theory fits the specific practice of SI.

\section{Intratextual coherence}

It is a basic tenet of the skopos theory that the target-text recipients (generally) do not compare the translation with the source text but treat it as a text in its own right within the target culture (cf. Reiss \& Vermeer 1984:115). The crucial standard to be met by any product of T\&I is the degree to which it is "coherent", i.e. understandable, "interpretable", meaningful within its particular situational context in a given targetcultural environment. The term "intratextual coherence", as used by Vermeer $(1978,1983)$ in formulating the general principles governing T\&I, may be somewhat misleading, though. In the skopos theory "intratextual coherence" refers not so much to relationships between propositional elements within the text or to a particular text-linguistic standard of textuality (Beaugrande \& Dressler 1981) but to a sort of "global" quality, to the coherence relationships between the purpose, meaning, form, and effect of the text. Evidently, the communicative patterns and expectations within a given culture will play a key role in determining whether a text is deemed sufficiently "coherent". (For a more detailed discussion of the problem of coherence see Pöchhacker 1993a.)

An analysis of the intracultural communicative coherence of a (target) text could thus be envisaged with reference to the structural, thematic, stylistic, lexical etc. conventions (Nord 1991a, 1991c) established for a given text type in the target culture. In terms of the theory of translational norms (Toury 1980, Shlesinger 1989b, Hermans 1991), a translated text would be examined for the extent to which it fits the demands for explicitness, order, clarity etc. made on comparable native texts (parallel texts) in the recipient culture. Chesterman (1993) speaks 
of such product norms as expectancy norms. (Cf. also his discussion of "convention" vs. "norm".)

The product norm now has to be correlated with the relevant production norms for SI. (For a more complete discussion of translational norms with respect to interpreting studies, see Schjoldager 1994 and (this volume).) One of the most important professional norms, in Chesterman's (1993) terminology, would seem to be the "equivalence of effect" commonly demanded of a good interpretation by authorities in the field. There are numerous references in the literature on interpreting to the effect that an interpretation should sound like an original speech, and that it is at its best when listeners forget that they are listening to an interpreter rather than the original speaker. Seleskovitch (1978), in particular, stresses the naturalness of the interpreter's output in the target language, and AIIC admonishes its new and would-be members to "put on a convincing act" by stating: "Make your public forget they are "only' listening to an interpretation." (AIIC 1982:6)

In a functionalist account, the target text in SI is expected to be functionally similar to the original speech (functional invariance); in terms of some of the familiar dichtomies in translation theory, a simultaneous interpretation would usually be expected to be of the "communicative" rather than "semantic" (Newmark 1981), "covert" rather than "overt" (House 1981), or "instrumental" rather than "documentary" type (Nord 1991a).

Being a manifestation of "instrumental" T\&I, the target text in SI would need to be as "conventional" (acceptable, appropriate, informative, correct, marked etc.) by target-cultural standards as the source text within the communicative traditions of the source culture. On the general assumption that a given culture is essentially different from, rather than similar to, another culture, the target text in SI will have to be adapted to the communicative patterns and text-type conventions (expectancy norms) generally accepted for native texts in the culture in question.

\section{Culture}

The "culture in question" of course raises the fundamental "question of culture". In the framework of functionalist T\&I theory, the search for a 
dividing line between language and culture is considered futile. Culture is embodied as much in what people do and what they know as in how they do it and how they talk about what they know (cf. Snell-Hornby 1988:39f). When studying T\&I as a process of cultural transfer, however, only a small fraction of culture-specific (or non-universal) phenomena will actually come under descriptive scrutiny: it is the textualized portion of the socio-cultural background (cf. Hönig \& Kussmaul 1982:58) which can be assessed in terms of its intracultural fit with established conventions or "correctness notions" (Hermans 1991:166). (In the next section a few assumptions regarding text-type conventions for conference speeches, such as forms of address and humor, will be investigated with regard to the extent of cultural transfer accomplished in an authentic corpus of professional SI.)

Narrowing down the study of "cultural transfer" in SI to particular text-type conventions leaves unresolved the problem of defining the scope of these cultural conventions, i.e. the size and make-up of the group of persons (language users) who recognize a given set of conventions. In the context of translation theory, language and culture tend to be situated on some sort of "national" level, e.g. French as the language of France and part of French culture, Greek as the language of Greece and part of Greek culture, Japanese as the language of Japan and part of Japanese culture, and so on and so forth. Vermeer (1983) has suggested the term paraculture to refer to culture at the level of a people, nation or society. Obviously, though, things are far more complicated than that. As we all know, there is any number of bilingual, trilingual and even multilingual countries (depending on the definition used, one may well wonder whether there is such a thing as a monolingual society at all), and there are many cases where the relation between "linguistic group" and "country status" has changed at the whim of political history; former Yugoslavia is just one (sad) example.

Moreover, a "national society" is structured not only on a regionalhistorical basis but also along the lines of social classes or, more likely nowadays and more relevant to the topic of conference interpreting, professions and interest groups. Vermeer (1983) labels this sort of subgroup within a paraculture as a diaculture and cites "German soccer fans" as an example. He also introduces the term idioculture to denote the behavioral and communicative conventions that one single person has developed for him/herself. As any interpreter and translator will 
know from doleful experience, such idiocultural phenomena on the part of the speaker (writer) can pose a special challenge to the operation of cultural transfer. In the examples from the case study discussed below, however, the emphasis will be on the relationship between paraculture and diaculture in the situational context of SI.

\section{Evidence from a case study}

The conference analyzed for a comprehensive descriptive study of SI (Pöchhacker 1994) was the 36th World Congress of the ICSB, the International Council for Small Business (June 24-26 1991, Vienna), a three-day scientific-technical congress in the field of small business management. The conference languages were English and German, with simultaneous interpretation provided for all sessions scheduled in the plenary room. The six sessions comprising the corpus were the Opening Session, Family Business Workshops I and II, the Standards Workshop, the Joint-Ventures Paper Session, and the Closing Plenary. Close to 50 conference speakers and three interpreters (Sî-A, Sî-B, and Sî-C) produced a total of roughly 150 (source and target) texts of over 14 hours duration.

Within the confines of this paper I shall have to infringe upon the principle of holistic documentation and analysis as represented in Fig. 2 and cite examples without systematically providing all analytical data. (For a detailed account of the ICSB corpus see Pöchhacker 1994, chapters 8 and 9.)

\section{Forms of address}

In translation theory, forms of address (as in business letters vs. personal correspondence, for instance) are often cited as a typical example of culture-specific text-type conventions (e.g. Vermeer 1994:8f). Given the much more direct and personal type of interaction in a conference situation, this issue seems even more relevant for the theory of interpreting. Nevertheless, to my knowledge, it has so far received little, if any, attention.

In the Opening Session of the ICSB Congress, the presidents of the international organization (ICSB) and its regional European affiliate (ECSB), two distinguished university professors by the names of KIRCHHOFF (USA) and MUGLER (Austria), address one another on 
42

the podium. When Mugler, the organizer and chairman of the Congress, addresses his international counterpart in English as "BRUCE", interpreter A (English $\rightarrow$ German) turns this into "PRÄSIDENT KIRCHHOFF". Similarly, the Executive Secretary of UNECE, a former Austrian ambassador, is addressed as "BotschAFTER HiNTEREGGER" (Ambassador Hinteregger) by interpreter B (English -> German) whereas in the English original he is simply "MisTER HiNTEREGGER". In the workshop sessions, English-speaking chairpersons frequently call speakers by their first names whereas more often than not they are addressed as "Herr ..." (= Mr) and "Frau ..." (= Mrs) in the German interpretation.

A particularly good example is the German interpretation (by interpreter B) of the chairman's remarks indicating the transition from the statement by "Mister SLOAN" to the speech by "MiSTER KAO" in the Closing Plenary (see Fig. 3).

Fig. 3: Excerpt from the Closing Plenary of the ICSB corpus. 
While the representative of a US entrepreneurs' association remains "Herr Sloan", the latter is addressed as "Herr Professor KaO" - a choice which proves fully justified in the course of the speech, since the speaker mentions both his colleagues in academic circles and his graduate students at university. One might speculate whether the interpreter's hesitation on the word "IST" was linked to his having a look at the printed conference program, which lists "Raymond W.Y. KAO" with the affiliation "University of Toronto"; without a video camera in the booth, however, such causal explanations are purely conjectural.

As regards interpretation in the opposite direction, interpreter $\mathrm{C}$ (German -> English) is confronted with some typically Austrian titles such as "Magnifizenz", "Kommerzialrat", "DiplomkaufManN", and "DiPLOMINGENIEUR" in the welcome address by MUGLER, the conference president, and handles them by means of "zero translation". Incidentally, MUGLER delivered the first $6^{1 / 2}$ minutes of his opening address in English (interpreted into German by Sî-B) and then switched over to German for a central portion of his speech ( $2^{1 / 2} \mathrm{~min}$.), in which he welcomes Austrian office-holders and high-ranking officials with complete titles and honorifics. This switch to German (with interpretation into English by Sî-C) was probably motivated by the speaker's wish to address fellow Austrians directly, but maybe also by his awareness of the difficulty or impossibility of rendering the many culture-bound terms and titles into English. Indeed, if MUGLER had welcomed his Austrian guests in English according to English conventions, i.e. without giving the peculiarly Austrian designations and titles, the interpretation into German, to which the guests addressed by MUGLER would have listened, might well have sounded much less polite. For the interpreter to turn a simple "Mister" into a "Kommerzialrat", "Diplomingenieur" or "Landesrat" would require a thorough briefing and good cooperation with the speaker before the conference session.

These few examples are not systematic enough to be used as evidence for a norm governing the handling of titles and forms of address in SI from English to German and vice versa. The problem is not so much the limited size of the corpus or the small number of interpreters but the fact that the appropriateness of applying the sort of strategy illustrated above cannot be judged without recourse to a full documentation of the constellation of interaction: How much does the 
interpreter know about the speaker (the listeners, the person addressed by the speaker)? How much does the interpreter know about how much the speaker knows about the person addressed by him/her? etc. Of course, "knowledge about an interactant" is not the only relevant parameter; other sets of questions could and would have to be asked and answered - for the analyst to judge which degree of formality, familiarity or explicitness best fits the expectancy norms in a given situation and culture. Nevertheless, the English-German examples cited above indicate that, at least in the case under study, the interpreters are making their interpretation conform to target-cultural conventions and some form of "cultural transfer" is indeed at work in SI.

\section{Humor}

What makes this kind of adaptation to target-cultural expectations work is the small size of the units of transfer. Since simultaneous interpreters are limited by the capacity of their short-term memory to transfering successive segments the size of, say, a clause, larger rhetorical units like anecdotes or examples cannot be adapted or transformed as a whole, even if they make little or no sense at all in the target text. A typical example of this sort of situation occurs in the Family Business Workshop II, when FRÖHLICH, an Austrian, speaking and apparently following the proceedings in English, comments on the way Americans pronounce the name of the Austrian-born economist "Schumpeter" (Fig. 4): 
Fig. 4: Excerpt from Family Business Workshop II of the ICSB corpus.

For those using the interpretation into German, few as they may have been, the information that the name "Schumpeter" is pronounced differently in English and that the speaker prefers to use the German pronunciation in his English presentation, is perfectly gratuitous. While the name is mentioned repeatedly in the course of the conference proceedings, its pronunciation in German is always the same, be it in the German speech by SCHÜSSEL, the Austrian Minister of Economic Affairs, or in the German interpretation (by Sî-A) of the statement by KIRCHHOFF, to whose American pronunciation FRÖHLICH is alluding. The remark by FRÖHLICH is clearly addressed to (American) English-speaking listeners and is not directly relevant to those listening in German. Nevertheless, it is impossible for the interpreter to drop the interjection in the German target text; what is more, the mock American pronunciation by Sî-B introduces a variant which does not even accurately reflect or document KIRCHHOFF's original, which triggered off FRÖHLICH's remark in the first place.

Jokes and funny stories embedded in a speech are among the challenges most dreaded by simultaneous interpreters. Not being able to foresee whether there will be a punch-line or whether the punch-line can be made funny in the target culture, the interpreter is usually 
doomed to follow the speaker to a nail-biting finish and hope for the best. More often than not, humor in one culture is not easily transferable to another, and (target-text) listeners who are left with an anticlimactic comment like "That's a pun in ... that cannot be rendered in ..." while people in the seats next to them are roaring with laughter surely cannot be expected to find the speech as functional and coherent in the interpretation as source-text listeners do in the original. Fig. 5 below provides an example for this type of situation: Sî-A, unwary of the pun to be developed from the English term "one-armed", follows the speaker to the punch-line and, realizing that the pun cannot be rendered in English, interjects the explanation "DAS_IS EIN WORTSPIEL IM ENGLISCHEN" (This is a pun in English) in the documentary-style interpretation. (For further discussion on this point, see Pöchhacker 1993b.)

Fig. 5: Excerpt from the Opening Session of the ICSB corpus. 
Even if an untranslatable funny remark is short enough to be left out or glossed over, the problem remains that half the audience is laughing and the other half is wondering what there is to laugh about. Thus, the successful handling of jokes in SI ultimately depends not on a professional strategy for cultural transfer but on the random coincidence between particular items of two languages and cultures.

Nevertheless, let us assume for a moment that the interpreter is lucky and manages to make all the jokes and funny remarks of the speaker (a Californian management theorist, let's say) as "laughable" in German as in the English original. Would this be a case of "functional equivalence"? I suspect not, even though English-German contrastive text-type research has not come far enough to provide me with conclusive proof. Still, British or American speakers are said to be casual and sprinkle their talks with humorous bits while Germans are supposed to lecture in a formal, factual and neatly ordered way. To German listeners with such stereotypical expectations, a foreign lecturer who has risen to guru status in his/her own culture but gives a talk by stringing up one personal anecdote after another might appear shallow, vague and unscientific (as well as overrated and overpriced). Conversely, a German speaker might come across as dry, meticulous, boring or intellectually pale if the text-type conventions of his/her native culture were interpreted "documentary-style". If such stereotypes were to be corroborated by vast amounts of empirical research on speeches at particular types of conferences (!), the conclusion for the practice of SI would be that the sort of adaptation to target-cultural conventions required for functionally invariant "instrumental" T\&I is not feasible under the processing conditions of SI (cf. also Albrecht 1990). This would mean that the functionalist approach is not equally applicable to this particular form of T\&I - or is it?

The reasoning followed above overlooks some important situational factors which characterize modern-day international conferencing in general and scientific-technical meetings such as the ICSB Congress in particular. More often than not, persons attending international meetings have a certain familiarity with other languages or cultures or, at any rate, are ready and willing to engage in some sort of cross-cultural contact. Conference participants therefore may not even expect or wish to have all "foreignness" of the original speech filtered out, as it were, by the interpreter; after all s/he is deliberately interacting with someone 
from abroad (cf. Seleskovitch 1978:114f). On the other hand, people also get sent off to conferences and meetings in the line of duty and may then expect the simultaneous interpretation to make communication as smooth and cross-culturally effortless as possible. If this were the typical state of affairs, there is another factor which, in some way, "takes the culture out of conferencing".

\section{Whose culture is it anyway?}

While training in SI may conceivably be offered in any spoken language, there is no denying the fact that the number of major conference languages and thus the number of frequently used language combinations is rather small. What is more, in principle and most notably also within the EU, all languages are equal, yet some languages are more equal than others. A case in point are the working languages of international associations, even in the field of T\&I (such as FIT, the International Federation of Translators, and EST, the European Society for Translation Studies). Chances are, therefore, that if a German translatologist wanted to have a discussion with a Danish colleague, the two would communicate in English.

The use of English as the lingua franca in conferences is of course particularly common in scientific-technical meetings. Take the - rather extreme - example of the ICSB Congress: The conference, with only two working languages, brought together a total of 413 participants from 40 countries. One third of the participants came from (eight) countries in which English is an official language, one fifth of them came from German-speaking countries. The rest of the participants came from 29 different countries in which German is of little significance. Thus, four fifths $(80 \%)$ of the participants would have followed and contributed to the proceedings in English.

This distribution, gleaned from the official list of participants, is clearly reflected also in the corpus of texts. Over 92\% (96 out of 104) of the "texts" (lasting from 3 seconds to 33 minutes) were in English. Only eight participants actually spoke German whereas nine speakers with German as their native language chose to speak English on the conference floor. 29 (out of 104) speeches were delivered by native speakers of English while no fewer than 67 speakers used English as an international auxiliary language (to use a more politically correct term, although "foreign language" would more aptly describe the sort of speech 
delivered in many of these cases). In terms of the duration of the sourcetext material, one fourth $(24.4 \%)$ was native English, one fifth $(21.1 \%)$ native German and more than half $(54.5 \%)$ was produced in non-native English. Thus, English was spoken $80 \%$ of the time, perfectly matching the figure of $80 \%$ calculated for the linguistic dominance of English from the list of participants.

In light of these statistics, the assumption of a cultural transfer on the conference floor becomes problematic if one imagines a Hungarian listening to the interpretation into German of what a Mexican is saying in English, to use an authentic example. The fact that smooth communication in such a culturally complex constellation is possible at all may be attributable to the very nature of this cultural complexity. Based on the notion of paraculture (Vermeer 1983), one would be dealing with two pairs of paracultures in God knows what relationship to one another. I would therefore suggest that this constellation is best explained with reference to the notion of a diaculture (Vermeer 1983), a group culture defined by the shared professional background, common technical expertise and, of course, a history of interaction as members of the ICSB. This particular expert culture transcends national-societal borderlines and could thus be called an international diaculture. The point is that, for the purpose of communication in the conference setting, participants have more "cultural" common ground (in terms of what they know and do, and how) than there are cultural barriers actually separating them by hampering communication. This view is strongly supported by the very high rating given to the feature "cultural homogeneity of group" in the survey on conference prototypes. The highest rating for this feature was obtained for hypertext type 2 ("technical conference") as shown in Fig. 1.

The "culture" in the languages used is still there, of course, but it is not as relevant to the process of trans-cultural communication. In other words, communication with SI at a conference such as the ICSB Congress rather takes place within one (international dia-)culture as a process of transfer between language-cultures.

The account provided here must not be misconstrued as advocating SI as mere linguistic transcoding. Rather, it is meant to point to the full complexity of SI as a highly specific manifestation of translatorial activity and suggest the need for much further work towards 
broadening and refining the theory base as well as expanding the body of empirical data available for corpus-based analyses.

\section{Conclusion}

This paper has charted an extensive course from the highly abstract general theory of T\&I to the highly specific practice of SI at an international conference. I hope that it has gone some way toward showing

(1) that by drawing on common theoretical concepts and models, translation studies and interpreting studies might discover more ways of benefiting from each other's insights and results,

(2) that the concepts of modern functionalist translation theory are rich enough to allow for stimulated discussion when applied to a holistic conception of the practice of conference interpreting,

(3) that general theoretical principles of T\&I, however rich, can be little more than points of departure for further elaboration and refinement by empirical research, and

(4) that interpreting researchers have their work cut out if they accept to take on the challenge of studying not only the process but also the product of professional interpreting in a comprehensive and complex framework centered on text-in-situation-\&-culture.

\section{References}

AIIC (1982): Practical Guide for Professional Interpreters. Genève: Association Internationale des Interprètes de Conférence.

Albrecht, Sigrid (1990) "Simultandolmetschen - komplexes transkulturelles Handeln?" TEXTCONTEXT 5, 166-208.

Beaugrande, Robert-Alain de \& Dressler, Wolfgang Ulrich (1981): Introduction to Text Linguistics. London/New York: Longman.

Chesterman, Andrew (1993) 'From 'Is' to 'Ought': Laws, Norms and Strategies in Translation Studies.” Target 5:1, 1-20.

Dillinger, Mike (1990): "Comprehension during interpreting: What do interpreters know that bilinguals don't?" The Interpreters' Newsletter 3, 41-58.

Gile, Daniel (1988): "An overview of conference interpretation research and theory". In: D. L. Hammond (ed.) (1988) Languages at Crossroads. Proceedings of the 29th Annual Conference of the American Translators Association. Medford NJ: Learned Information, 363-371. 
Gile, Daniel (1989): “Les flux d'information dans les réunions interlinguistiques et l'interprétation de conférence: premières observations". Meta 34, \#4, 649-660.

Gile, Daniel (1990): "Scientific Research vs. Personal Theories in the Investigation of Interpretation". In: L. Gran \& Ch. Taylor (eds.) Aspects of Applied and Experimental Research on Conference Interpretation. Udine: Campanotto, 28-41.

Gile, Daniel (1991): "The processing capacity issue in conference interpretation". Babel 37, \#1, 15-27.

Herbert, Jean (1952): Manuel de l'Interprète. Genève: Georg.

Hermans, Theo (1991): "Translational Norms and Correct Translations". In: K. M. van Leuven-Zwart \& T. Naaijkens (eds.) Translation Studies: The State of the Art (Approaches to Translation Studies 9) Amsterdam/Atlanta GA: Rodopi, 155-169.

Hönig, Hans G. \& Kussmaul, Paul (1982): Strategie der Übersetzung. Ein Lehr- und Arbeitsbuch (Tübinger Beiträge zur Linguistik 205) Tübingen: Narr.

Holz-Mänttäri, Justa (1984): Translatorisches Handeln. Theorie und Methode (Annales Academiae Scientiarum Fennicae B 226) Helsinki: Suomalainen Tiedeakatemia.

House, Juliane (1981): A Model for Translation Quality Assessment (Tübinger Beiträge zur Linguistik 205) Tübingen: Narr.

Kopczynski, Andrzej (1994): "Quality in conference interpreting: Some pragmatic problems". In: Snell-Hornby et al. (eds.), 189-198.

Kurz, Ingrid (1993): "Conference interpretation: Expectations of different user groups.” The Interpreters' Newsletter 5, 13-21.

Lakoff, George (1987): Women, Fire, and Dangerous Things. What Categories Reveal about the Mind. Chicago/London: University of Chicago Press.

Lederer, Marianne (1978): "Simultaneous Interpretation - Units of Meaning and other Features”. In: D. Gerver \& H. W. Sinaiko (eds.) Language Interpretation and Communication. New York: Plenum Press, 323-332.

Lederer, Marianne (1981): La traduction simultanée - expérience et théorie. Paris: Minard-Lettres Modernes.

Matthews, John (1984): "Notes on consecutive interpretation. 1." Cuadernos de Traducción e Interpretación \#4, 85-90.

Namy, Claude (1978): "Reflections on the Training of Simultaneous Interpreters - A metalinguistic approach". In: D. Gerver \& H. W. Sinaiko (eds.) Language Interpretation and Communication. New York: Plenum Press, 25-33.

Newmark, Peter (1981): Approaches to Translation. Oxford: Pergamon Press.

Nord, Christiane (1991a): "Scopos, Loyalty, and Translational Conventions." Target 3:1, 91-109.

Nord, Christiane (1991b): Text Analysis in Translation. Theory, Methodology and Didactic Application of a Model for Translation-Oriented Text Analysis. Amsterdam: Rodopi. 
Nord, Christiane (1991c): "The Role and Scope of Conventions in Translation". In: M. Jovanovic (ed.) Proceedings of the XIIth World Congress of FIT, Belgrade 1990. Belgrade: Prevodilac, 85-97.

Pöchhacker, Franz (1992): "The role of theory in simultaneous interpreting”. In: C. Dollerup \& A. Loddegaard (eds.) Teaching Translation and Interpreting. Training, Talent and Experience. Amsterdam/Philadelphia: Benjamins, 211-220.

Pöchhacker, Franz (1993a): "From knowledge to text: Coherence in simultaneous interpreting". In: Y. Gambier \& J. Tommola (eds.) Translation and Knowledge. Turku: Centre for Translation and Interpreting, 87-100.

Pöchhacker, Franz (1993b): “'This isn't funny.' A note on jokes in simultaneous interpreting". In: C. Picken (ed.) Proceedings of the XIIIth World Congress of FIT. Vol. 1. London: Institute of Translation and Interpreting, 455-464.

Pöchhacker, Franz (1994): Simultandolmetschen als komplexes Handeln (Language in Performance 10) Tübingen: Narr.

Reiss, Katharina (1971): Möglichkeiten und Grenzen der Übersetzungskritik. Kategorien und Kriterien für eine sachgerechte Beurteilung von Übersetzungen (Hueber Hochschulreihe 12) München: Hueber.

Reiss, Katharina \& Vermeer, Hans J. (1984): Grundlegung einer allgemeinen Translationstheorie (Linguistische Arbeiten 147) Tübingen: Niemeyer.

Schjoldager, Anne (1994): "Interpreting Research and the 'Manipulation School' of Translation Studies." Hermes 12, 65-89.

Schjoldager, Anne (this volume) "An exploratory study of translational norms in simultaneous interpreting: Methodological reflections."

Seleskovitch, Danica (1978): Interpreting for International Conferences. Washington DC: Pen \& Booth.

Shlesinger, Miriam (1989a): Simultaneous Interpretation as a Factor in Effecting Shifts in the Position of Texts on the Oral-Literate Continuum. Unpubl. M.A. thesis. Tel Aviv University.

Shlesinger, Miriam (1989b): "Extending the Theory of Translation to Interpretation: Norms as a Case in Point". Target 1:1, 111-115.

Snell-Hornby, Mary (1988): Translation Studies - An Integrated Approach. Amsterdam/Philadelphia: Benjamins.

Snell-Hornby, Mary, Pöchhacker, Franz \& Kaindl, Klaus (eds.) (1994): Translation Studies. An Interdiscipline (Benjamins Translation Library 2) Amsterdam/Philadelphia: Benjamins.

Snelling, David (1989): “A Typology of Interpretation for Teaching Purposes”, in: L. Gran \& J.M. Dodds (eds.) The Theoretical and Practical Aspects of Teaching Conference Interpretation. Udine: Campanotto, 141-142.

Stenzl, Catherine (1983): Simultaneous interpretation: Groundwork towards a comprehensive model. Unpubl. M.A. thesis. London. 
Toury, Gideon (1980): In Search of a Theory of Translation. Tel Aviv: The Porter Institute.

Vermeer, Hans J. (1978): "Ein Rahmen für eine allgemeine Translationstheorie." Lebende Sprachen 23, 99-102.

Vermeer, Hans J. (1983): Aufsätze zur Translationstheorie. Heidelberg.

Vermeer, Hans J. (1989): "Skopos and commission in translational action". In: A. Chesterman (ed.) Readings in Translation Theory. Helsinki: Oy Finn Lectura Ab, 173-187.

Vermeer, Hans J. (1994): “Translation today: Old and new problems". In: Snell-Hornby et al. (eds.), 3-16. 
